\title{
Impact of financial inclusion and green bond financing for renewable energy mix: implications for financial development in OECD economies
}

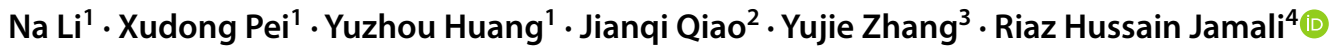

Received: 4 October 2021 / Accepted: 12 November 2021 / Published online: 29 November 2021

(c) The Author(s), under exclusive licence to Springer-Verlag GmbH Germany, part of Springer Nature 2021

\begin{abstract}
The study aims to empirically estimate the nexus of green bond financing with renewable energy index OECD countries. Using the OECD countries data over the period of the 2011-2019, the study estimated the nexus between constructs. To justify the study findings and present widespread policy implications on recent topicality Padroni unit root test, FMOLS and DOLS technique is applied. For robustness analysis, long-run sensitivity analysis using FMOLS extension is used, and a comparative picture of green bond financing nexus with renewable energy index is presented. The study presented the consistent effects of green bond financing on renewable energy index indicators. This asymmetrical role of green bonds is confirmed on renewable energy indicators over the sample period. OECD countries injected $31 \%$ role of green bond financing on renewable energy index constructs, and it raised $9.4 \%$ of per unit energy efficiency in renewable energy systems; by this, the study findings warrant maximum support through public office, energy ministries, and departments for energy efficiency optimization. The study presents multiple policy implications to enhance renewable energy generation for energy efficiency through different alternative sources. Despite growing literature, the empirical discussion on this topicality is still shattered and less studied, which is extended and contributed by recent research. Furthermore, efficient regulation in the renewable energy sector may convert financial uncertainty into a huge opportunity. Investing in renewable energy stocks might help investors diversify their portfolios.
\end{abstract}

Keywords Financial inclusion · Financial development · Green bond financing · Renewable energy index · Energy efficiency $\cdot$ OECD countries

\section{Introduction}

The use of renewable energy (RE) in large quantities has a lot of potential. Except for Singapore, which has significant

Responsible Editor: Nicholas Apergis

Riaz Hussain Jamali

jamalirh@yahoo.com

land constraints, the International Energy Agency (IEA)

$\mathrm{Na} \mathrm{Li}$

linanrhj@gmail.com

Xudong Pei

peixudong888@163.com

Yuzhou Huang

yzhuang1984@163.com

1 School of Economics and Management, Xi' an Shiyou University, Xi' an 710065, China

2 School of Economics and Management, Xi' an University of Technology, Xi' an 710048, China

3 Business Economics Group, Wageningen University and Research, $6700 \mathrm{HB}$ Wageningen, The Netherlands

4 School of Economics, Sichuan University, Chengdu 610065, China

Jianqi Qiao

1170510005@stu.xaut.edu.cn

Yujie Zhang

zhangyujieyx@hotmail.com 
predicts that each ASEAN member state would be able to produce between 120 and $400 \mathrm{TWh}$ of renewable energy annually by 2030 (Kothari et al. 2010). Despite supporting laws and increasing cost-competitiveness of RE projects1, there is still a large investment gap in the industry. According to research by Sustainable Energy, for all, achieving global 50 percent renewable energy generation by 2030 would need a funding deficit of US\$167 billion per year (Demirtas 2013). Despite their high ambitions, the results reveal a lack of investment in the renewable energy sector. According to academic studies, the region's ability to meet its RE investment goals is hampered by a financing deficit. As a consequence, it's essential to investigate the underlying causes of the region's financing gap and provide solutions to ensure that sufficient funds through green bond financing (Goldemberg 2007). More so, these funds are channeled into the renewable energy sector to fulfill the region's long-term energy needs in a sustainable manner (Chu and Majumdar 2012).

Biofuels have long been considered essential to a nation's economic structure. Economic growth depends on it, particularly in difficult times. Renewable energy sources include the sun, wind, waves, rivers, tides, radioactive decay in the earth's mantle, and biomass. This year's US (RE) output record of 11.6 quadrillion BTUs is up to $17.7 \%$ from 2015 (Shafie et al. 2011). It is estimated that by 2040, OECD nations would contribute for two-thirds of global energy investment, according to a case study (Tester et al. 2012). In the oil sector, COVID-19 struck today, just as RE was gaining traction. COVID-19 pandemic's infectious effects have recently been recognized as having significant consequences, especially in the RE (Hussain et al. 2017). Energy has been hit hard by the world's worst pandemics. New energy studies show that the epidemic has compounded problems already present in global supply networks (RE). Energy Information Administration (EIA) reports that investor confidence in all energy resources has decreased due to widespread uncertainty, which may harm renewable energy transitions (Jacobson and Delucchi 2009). Consider the impact of market and policy uncertainty on wind energy investment when using a dynamic optimization model Because of the risks associated with policy uncertainty, investors see real estate investments as riskier (Naber et al. 2017).

The present COVID-19 crisis has never seen such dramatic reductions in global energy investment. During the West African Ebola virus epidemic, energy production dropped, wiping away many of the previously gained advantages (2013-2016). IEA data from 2003 show that, despite the high degree of uncertainty surrounding the outbreak of the (SARS) pandemic in 2003, during periods of complete lockdown, many countries' power usage dropped by as much as $20 \%$ or more, resulting in a loss of 5 billion cubic meters of natural gas. According to Bloomberg (2020), the number of renewable energy contracts signed by US companies this year will be less than the 13.6 gigawatts peak reached last year. Additionally, all shipments of solar panels from China have been halted, putting the country's solar energy industry at serious risk.

After the global financial crisis of 2008-2009, investors will be increasingly interested in understanding the dynamics of return on capital (ROE) in order to adequately respond to new possibilities in a series of market scenarios (GFC). Investors who were affected by the Great Recession are more sensitive. According to previous studies, institutional investors must get more involved in capital market (RE) investments in order to meet the sector's financing needs. According to Jha and Puppala (2017), when the deployment of RE grows, investors may be able to earn substantial gains by investing in RE stocks. Energy policy analysts are keeping an eye on RE stocks in these emerging stock markets to determine whether they provide new investment opportunities (Liao et al. 2021). Some studies dig even further into the literature on financial contagion and spillover effects to see which financial crises have been compared to infectious illnesses and to see how the levels of uncertainty around pandemic impacts and economic policy vary (Roselli et al. 2019).

As a consequence, from January 3, 2005 to June 30, 2020, we pay careful attention to how the World Pandemic Uncertainty Index (WPUI) impacts the Real Estate Index (RE). Researchers can use this index to understand how often phrases such as "pandemic" and "disease epidemics" appear in the Economist Intelligence Unit's national reports. Due to the financial crisis and growing bias in North America and Europe, the new economic strategies are reflected in the risk and return on investment of (RE) projects (Shahbaz et al. 2020). The present study is based on Hamilton's groundbreaking work from 1983, which indicates that economic policy uncertainty and energy use are inextricably linked, regardless of differences in un-favorable outcomes. Because of the variations in resource endowments, replenishment capacity, and manufacturing development phases between (RE) companies and other power firms, the consequences of economic risk in an environment where government policy is uncertain may also be different for this sector.

Academics have theorized how public policy uncertainty inhibits real estate investment to a significant degree (RE). According to research, supply/demand disruptions induced by Serious economic instability may have a big impact on investment choices regarding (RE) consumption and the investment structure's energy system optimization. For example, when economic policy is unclear, conventional energy businesses make better investments, but this is not reflected in renewable energy company investments, according to Liu et al. As a result, the study claims that the short-term costs of building 
wind farms have not risen much (EPU). Furthermore, research indicates that uncertainty regarding the federal government's decision limits investors' options in wind energy. According to study, China's energy and real estate (RE) firms make irrational investment decisions, resulting in wasteful expenditure at the expense of investors.

Funding channels and cost of capital are two elements of the renewable energy project economics may be used to analyze funding gaps. The cost of capital is related to the cost of acquiring the funds, which refers to the pool of funds available for renewable energy projects. The ability of a project to enter the implementation and operational phases is directly influenced by the availability of financial resources. Most renewable energy projects are funded by a combination of equity and debt. Renewable energy projects in developing countries will require greater capital inflows (30-40\%) (UNEP, 2007) because bank loans available in mature economies are insufficient. As a result, renewable energy project developers in poor countries face intense pressure to raise funds, and if they don't, projects often fail.

This article attempts to offer a thorough knowledge of the reasons of Asia's funding gap, as well as strategies to close it. The study then suggests that fixed income security products, such as bonds, be used to bridge the funding gap. Three distinct products will be examined in depth: national currency (LCY) corporate bonds, investment project securities, and finance debt securities. The (RE) index, which measures firms that offer financial services, is affected by policy-related market instability, is mostly unexplored (RE). Investment in real estate businesses may play a critical role in attaining long-term economic development due to the maximum return on the (RE) stocks than overall equities. This is a huge discrepancy. Cash subsidies, investment tax credits, expedited depreciation, transfer payments, and favorable tax policies are among the other government incentives available to assist RE projects get off the ground in the early phases of development. As a consequence, economic policy uncertainty may have a major effect on the Real Estate Index (RE). Policymakers are debating whether the significant changes in the (RE) index were caused by a disruption brought on by energy price volatility, stock market instability and lack of information, and carbon emission pricing volatility during uncertain times. These findings will help us better understand how the (EPU) effects the RE index, which is currently unknown. We created a new index to serve as a stand-in for the S\&P 500 by tracking the frequency of newspaper stories containing specified keywords related to the economy, policy issues, and uncertainty using an automated search approach (EPU).

\section{Review of literature}

There seem to be two causes for the Asian funding gap (Wang et al. 2018a, b). To begin with, owing to capital market failures, renewable energy projects are at a financial disadvantage when compared to conventional power projects. Capital market defects may be caused by incomplete information, risk aversion, or agency problems. To begin, keep in mind that utility-scale renewable energy projects are often compared to more conventional fossil fuel-based projects by investors (Song et al. 2019). Because industry expertise is patchy, a lack of experience with lenders is a problem for the relatively young renewable energy sector (Hanif et al. 2021). Due to a lack of understanding of the industry's risks, such projects may be seen as having a higher risk, leading to investors anticipating higher returns to compensate for the higher risk they incurred. Furthermore, as compared to total expenditures, the initial capital costs of RE projects are significant (Liu and Hamori 2020). RE indicators are regarded as costlier and therefore less economically feasible by investors because of the large upfront costs, even though all other financing circumstances are the same. This is referred to as "front-loading."

In the renewable energy industry, a new breed of small and medium-sized companies (SMEs) has arisen, with smaller market capitalization and perhaps a poorer track record than more established conventional energy suppliers. As a result, under the current financial system, investors will be less interested in investing in RE SMEs since they are regarded to be less creditworthy than more established conventional energy businesses (Kumar et al 2020). RE developers face greater financing expenses and fewer financial instrument choices because of their modest size and lack of expertise. Established companies, for the most part, may use corporate finance to borrow money based on their balance sheet and return it over time with interest, depending on their capacity to repay the loan (Ahmad et al. 2021). Developers of real estate projects are an exception, since they lack the market capitalization and track record required to rely on other sources of financing. These smaller organizations will have no other choice than to use project financing (Caglar 2020), which is debt acquired based on an organization's capacity to repay a loan on a specific project (Li et al. 2021a, b, c). This kind of loan is usually costlier due to the higher associated risks (Alkathery and Chaudhuri 2021).

Unfortunately, the scope of such activities would have been severely limited owing to Asia's still-developing financial system. Banks still have influence over Asia's financial systems (Qin et al. 2021). The OECD area as a whole is heavily reliant on the banking industry, with 
capital markets playing a minor role. Because of their prominence in the financial sector, banks dominate the region's real estate financing. A bank may provide RE finance in the form of term loans, project loans, mezzanine loans, and refinancing. Term loans, according to the BNEF database, are a popular method to fund renewable energy projects throughout Asia, particularly in India and China. Banks will be better equipped to weather periods of crisis, thanks to the new Basel III rules, which require them to maintain liquid and high-quality assets. Long-term loans with no secondary market are penalized as a consequence of these liquidity restrictions. Real estate investment trust (REIT) loans, for the most part, fall under this category, making it more difficult for them to get bank financing (Nasr et al. 2020). It is also conceivable that borrowing costs may increase as a consequence of this. Because the new Basel III regulations are not anticipated to go into force for another year or two, banks may be reducing longterm lending in preparation for the new Basel III legislation (Yogee et al. 2020). Furthermore, RE efforts may have project structures that are less attractive to lenders due to their nature (Ram Ola et al. 2020). In the current funding climate, lenders prefer traditional energy projects with longer registrations, lower initial and maintenance costs, shorter payback periods, and government incentives for renewable energy projects (Alvarado et al. 2021). Incentives must be adjusted to promote a shift in preference toward renewable energy projects. Commercial banks in developing nations would also be forced to hold substantial energy-related assets from national utilities, limiting their ability to lend to the rapidly expanding renewable energy industry (Dawar et al. 2021).

Uncertainly, from a theoretical standpoint, assumed that a greater EPU level makes stock market investing more difficult, resulting in fewer corporate earnings and less self-raised company investment. To what extent does this idea still hold true for real estate equities today? The fact that $\mathrm{RE}$ requires a lot of money is a significant barrier. Renewable energy investments need a market environment that allows for more accurate pricing and profit forecasting than conventional markets (Anh Tu et al. 2021. On the other hand, the cost of capital in (RE) projects is typically regarded as a trade secret, and as a consequence, it is seldom revealed (Alemzero et al. 2021). Because most $\mathrm{RE}$ project finance arrangements include non-traded equity investments and bank loans, this is the case ( $\mathrm{Li}$ et al. $2021 \mathrm{a}, \mathrm{b}, \mathrm{c})$. The actual value of RE initiatives cannot be confirmed, according to a study of the financing mechanisms used by RE businesses at this moment (Iqbal et al. 2021). Uncertainty creates underdeveloped and dysfunctional RE stock markets, which are characterized by a lack of access to precise and reliable data (Li et al. 2021a, b, c).
The sensitivity of the RE index to an erroneous standard discount rate increases with time, according to this study. Using different measures of uncertainty, it is showed that $\mathrm{RE}$ stock return risks are more sensitive to financial market uncertainties, while EPU has a very small effect (economic policy, financial markets, and energy markets). According to the study, geopolitical worries have varied effects on energy returns and volatility, further complicating the issue. Despite the fact that EPU is not a major concern for companies, it is a source of consternation for real estate investors and energy regulators.

Earlier studies assumed that fossil fuels will continue to provide the overwhelming majority of global energy needs, and they looked at the transmission mechanisms from oil prices to electricity costs.

\section{Data and methodology}

\section{Data sources}

Green bond financing may help renewable energy mobilize funds, and this research examines how green bond financing might aid in this mobilization to develop testable hypotheses about the connection between green bond financing creation and the renewable energy index. It is noted that the weighting of enterprises and sectors in the (RE) index is determined by their contribution to the growth of the economy (RE). A wide range of economic and financial aspects are considered. All variables will be utilised following the register adjustment. The proportion of the phrase "uncertainty" and its fluctuations in the National Economist Intelligence Unit (EIU) report on green bond financing (Alola and Uzuner 2021; Zakari et al. 2021). However, as this research shows, renewable energy is a multibillion-dollar sector that still occupies just a tiny portion of the global energy market in OECD countries and other developed nations. In reality, renewables accounted for $10.8 \%$ of the OECD's total primary energy production in 2019. Faster expansion is thwarted by a number of financial risks and obstacles. Costwise, renewable energy sources compete with traditional fossil fuel ones. In comparison to other technologies, most renewable energy projects have poor return rates and large upfront expenditures. Many investors will only put money into a project if the developer agrees to conditions that are averse to him. For example, in 2019, investors in large renewable energy sources sought green bond financing and platforms that improved their knowledge of the operational and financial performance of their assets. They wanted to maximize their profit margins in an increasingly cutthroat industry. A new way of thinking and new kinds of finance are required for funding a renewable energy plant, according to the research. To make matters worse, according to 
their reasoning, the energy markets are not ideal because of the inaccuracies in project risk estimates and the resulting increase in transaction costs. Fund managers will need to utilize data to validate performance in 2020 if renewable energy is to become a preferred infrastructure investment.

The simplest method to use bonds for renewable energy funding is for renewable energy businesses to issue their own corporate bonds. The overall amount of RE company bonds issued has risen from $\$ 5.2$ billion in 2010 to $\$ 18.3$ billion in 2015. In terms of bond use, Asia has been in the forefront. Nearly all (nearly ninety percent) of Asia's renewable sector bonds originate from OCED nations, according to a recent report by the World Resources Institute (WRI). Increasing investment in developing nations RE sectors is a common occurrence. According to Li et al. ( 2021a, b, c), emerging nations like China accounted for more than half of worldwide RE infrastructure investment in 2012. However, for other Asian nations, the OECD countries serve as a successful example model.

\section{Models and methods}

In this empirical investigation, three models were calculated. The index $(R E)$ is the dependent variable $\left(R_{i t}\right)$. First, the impact of green bond financing and the renewable energy index is estimated using a conventional approach. This allows the renewable energy (RE) index to be compared to green bond funds. The following routines can be used to display the computed model:

These findings explore the connections between the use of renewable (and non-renewable) energy and economic development again in the future. As a result, we utilized a neoclassical production function that has been enhanced. As well as capital and labor, renewable (and non-renewable) resource usage is taken into account in this expanded production function. Using renewable energy index and green bond finance inputs, the following basic kind of enhanced production function is modeled:

$Y_{i t}=f\left(R E_{i t}, N R E_{i t}, K_{i t}, L_{i t}\right)$

where $i$ and $t$ stand for nation and time, respectively, and $Y_{i t}, R E_{i t}, N R E_{i t}, K_{i t}$, and $L_{i t}$ indicate renewable energy index and green bond financings. The conversion in the study constructs is further extended in Eq. (2) with the natural logarithm that delivers well-organized and reliable experiential outcomes.

$Y_{i t}=R E_{i t}^{\beta 1 i} N R E_{i t}^{\beta 2 i} K_{i t}^{\beta 3 i} L_{i t}^{\beta 4 i}$

The quantitative Eq. (2) is further converted into the augmented function which is converted as follows, $\ln Y_{i t}=\beta_{1 i} \ln R E I_{i t}+\beta_{2 i} \ln K_{i t}+\varphi_{i t}$

Here the $R E I_{i t}$ is the renewable energy index, and $K_{i t}$ is energy efficiency that is assessed in recent study, by testing the role of green bond financing. The $\varphi_{i t}$ indication indicates the error term of the study. More so, Eq. (3) is further converted into Eq. (4) to measure the unit root test,

$y_{i t}=\alpha_{i}+\beta^{\prime} X_{i t}+u_{i t}$

Through this equation, the study has shown no serial correlation,

$H_{0}: P_{i j}=P_{j i}=\operatorname{cov}\left(u_{i t}, u_{j t}\right)=0$ for $i \neq j$

$H_{1}: P_{i j}=P_{j i} \neq 0$

Now the product moment correlation disturbance is developed as,

$p_{i j}=p_{j i}=\frac{\sum_{i=1}^{T} u_{i t} u_{j t}}{\left(\sum_{t=1}^{T} u^{2} i t\right)\left(\sum_{t=1}^{T} u^{2} j\right)^{\frac{1}{2}}}$

The study extends the empirical estimation strategy by applying the Pedroni panel co-integration test. The motivation to use this technique is to infer the long-run co-integration to show among the study constructs. This technique is modeled in Eq. (6), given as follows,

$y_{i, t}=\alpha_{i}+\beta_{1 i} x_{1 i t}+\beta_{2 i} x_{2 i, t}+\ldots \cdots+\beta_{M i} x_{M i, t}+\varepsilon_{i, t}$

To infer the long-run elasticity of the Pedroni panel cointegration technique, fully modified OLS and dynamic OLD tests are also applied, and these both tests are empirically shown in following equations,

$Y_{i t}=\delta_{i}+\beta_{i} X_{i t}+\varepsilon_{i t}$

$Y_{i t}=\vartheta_{i}+x_{i t}^{\prime} \mu+\sum_{j=-p}^{p} \sigma_{i k} \triangle \chi_{i t+p}+e_{i t}$

For robustness of the study findings, we investigate the causality of the short-run dynamic bivariate panel by using a model that accommodates cross-sectional heterogeneity. A test for homogeneous non-causality versus the alternative hypothesis of heterogeneous non-causality is suggested by this method. The Granger causality test for heterogeneous panel data models is a simplified form of this causality test. With fixed coefficients, heterogeneous panel data models operate. The following is a representation of the linear equation,

$y_{i, t}=\alpha_{i}+\sum_{k=1}^{k} \gamma_{i}^{(k)} y_{i, t-k}+\sum_{k=1}^{k} \beta_{i}^{(k)} x_{i, t-k}+\varepsilon_{i, t}$ 
Previous energy economics studies have ignored crosssectional dependency and variability all across the experimental analysis. We utilized cross-sectional statistics for the exploratory work since that is what we had anticipated.

\section{Research data}

This research utilizes a mixed data set for 26 OECD countries from 2011 to 2019 to examine the effect of green bond financing startup formations on renewable energy usage. Based on the data available for all of the yearly time series in the empirical analysis, the study period and sample nations were selected. This (RENC) data measures renewable energy consumption and is represented in million tonnes of oil equivalents (Mtoe). GDPPC (gross domestic product per capita) is a measure of income in constant 2010 US dollars. As a proportion of GDP in constant local currency, gross domestic product per capita growth (GDPCG) is computed. Net expenditure to acquire a long-term management stake (10 percent or more of voting shares) in a company that operates in a different nation than the investor is measured by foreign direct investment (FDI). It displays net inflows as a \% of GDP for comparison. There is also a need to use the consumer price index (CPI) to approximate current energy costs since such data is not accessible for all OECD countries with available data or for all years.

\section{Results and discussion}

\section{Empirical outcomes}

Renewable energy consumption is favorably correlated with economic growth, and renewable energy index indicators are positively correlated with green bond financing, according to prior study. Similarly, the study's results suggest that some countries may continue to depend on non-renewable energy sources for future development rather than deploying renewable energy, since renewable energy consumption is negatively correlated with economic growth. Our findings also corroborate prior studies indicating that increased green bond financing resulted in an increase in renewable energy use regardless of the sample size.

Similarly, both the increase in oil costs and the increase in renewable energy use were positively correlated, which fits theoretical expectations and prior study results. The linear estimates for the OECD country samples indicate that growing trade openness had a varied effect on renewable energy consumption growth: it reduced growth in impoverished nations but increased it in rich OECD countries such as the UK. There may be some variation in the effect of renewable energy development drivers depending on the robustness of democratic institutions. The non-linear estimate formulation
Table 1 Average annual score of the energy poverty index in sample period (2011-2019)

\begin{tabular}{|c|c|c|c|c|c|}
\hline Countries & $\mathrm{Y}$ & $\mathrm{RE}$ & NRE & $\mathrm{K}$ & $\mathrm{L}$ \\
\hline Austria & 1.433 & 9.292 & 0.696 & 6.967 & 3.868 \\
\hline Belgium & 4.911 & 5.015 & 0.683 & 2.357 & 3,684 \\
\hline Czech Republic & 5.515 & 1.831 & 9.258 & 6.891 & 4.209 \\
\hline Denmark & 0.138 & 6.615 & 1.655 & 1.058 & 0.263 \\
\hline Estonia & 3.155 & 2.702 & 1.698 & 1.607 & 5.997 \\
\hline Finland & 4.936 & 0.904 & 0.135 & 0.058 & 8.855 \\
\hline France & 0.484 & 5.773 & 0.451 & 0.214 & 4.413 \\
\hline Germany & 1.365 & 7.271 & 5.953 & 0.126 & 4.691 \\
\hline Greece & 3.621 & 2.024 & 0.029 & 6.812 & 4.379 \\
\hline Hungary & 2.704 & 0.313 & 0.229 & 0.416 & 6.835 \\
\hline Iceland & 2.678 & 3.3973 & 0.257 & 1.204 & 1.095 \\
\hline Ireland & 5.473 & 2.774 & 0.851 & 1.509 & 3.218 \\
\hline Italy & 0.913 & 2.131 & 0.266 & 1.632 & 1.162 \\
\hline Latvia & 6.254 & 0.155 & 0.452 & 1.521 & 2.113 \\
\hline Lithuania & 8.215 & 7.256 & 0.282 & 0.845 & 9.806 \\
\hline Luxembourg & 0.221 & 1.271 & 0.085 & 9.631 & 2.195 \\
\hline Netherlands & 0.927 & 0.073 & 0.457 & 0.665 & 0.052 \\
\hline Norway & 4.337 & 4.107 & 0.535 & 0.285 & 0.766 \\
\hline Poland & 1.853 & 6.979 & 0.017 & 3.242 & 0.873 \\
\hline Portugal & 6.812 & 1.635 & 1.474 & 0.415 & 3.098 \\
\hline Slovak Republic & 6.871 & 5.425 & 0.081 & 0.182 & 4.173 \\
\hline Slovenia & 0.729 & 1.468 & 8.008 & 0.562 & 3.752 \\
\hline Spain & 1.059 & 1.682 & 0.101 & 0.703 & 1.596 \\
\hline Sweden & 4.059 & 4.669 & 6.981 & 9.255 & 1.717 \\
\hline Switzerland & 1.591 & 2.474 & 0.786 & 0.432 & 8.456 \\
\hline UK & 4.712 & 3.562 & 5.567 & 5.432 & 5.824 \\
\hline
\end{tabular}

and democracy as a threshold variable allow us to look at the relationship between renewable energy growth and its drivers. Table 1 shows the findings of this research, which used the modified Wald statistic to see whether standard inference could be drawn about the threshold variable. We reject the null hypothesis of a linear model at $10 \%$ and $1 \%$ significance levels when looking at entire nations and developing country samples, with Wald values of 16.3838 and 1 percent significance levels, respectively. The developed-nation results thus stay the same, and no additional findings for developednation countries are given because the linear model's null hypothesis for developed-nation countries is not rejected.

\section{Econometric analysis}

Fiscal devolution advances environmental quality; nonetheless the impact is greater when institutional quality is advanced. Unidirectional impacts are observed for the following parameters: fiscal devolution, gross domestic product, human resource indicator, eco-invention, carbon dioxide 
Table 2 Unit root test and cross-sectional loadings

\begin{tabular}{llllll}
\hline Constructs & Y & RE & NRE & K & L \\
\hline Pesaran CD & $2.256^{*}$ & $2.936^{*}$ & $9.141^{*}$ & $6.733^{*}$ & $5.664^{*}$ \\
Significance & 0.000 & 0.000 & 0.000 & 0.000 & 0.000 \\
Testing unit root test & & & & & \\
CIPS test (at level) & 3.829 & 2.159 & 6.314 & 2.067 & 2.626 \\
CIPS test (at 1st diff) & 0.291 & 4.861 & 1.143 & 0.829 & 6.652 \\
\hline
\end{tabular}

*Shows that the alternative hypothesis of CD test is accepted and unit root is significant at $5 \%$ level of significance

pollution, and state establishments. The experimental findings elaborately affirm that fiscal devolution and eco-invention expand RE use and reduce conventional energy use, i.e., conventional source. In addition, advancements in political perils indicators and growing R\&D in RE sources expand RE use and reduce the use of conventional fuel sources. Moreover, GDP expands conventional and clean energy sources of use, because it increases the spending power of the nations.

In order to arrive at this point, nations ought to whip up environmental consciousness on the general populace the need to keep a sustainable environment and formulate stringent ecological standard in achieving that. Besides, a greater proportion of financing in research and development will deliver low carbon sources to meet their energy use, hence negating pollution and protecting the environment. The findings of ecological sustainability in one unit of the South Asian countries are timely and plausible, as the nations are making efforts collectively and single-handedly to attain maximum environmental performance within the subregion. Table 2 shows unit root test and cross-sectional loadings.

Thus, the discovery of new renewable energy sources results in a greater usage of renewable energy in democratic countries than in less democratic ones, since the former take climate change problems more seriously than the latter. However, we find that real oil price changes are positively associated with renewable energy consumption in both samples for less democratic countries, indicating that oil prices are a significant factor in the shift to renewable energy consumption, but this effect is not significant for the democratic group. Renewable energy acquisition may have a negative effect due to the suggested reason, which includes a scarcity of well-studied energy resources, especially renewables. Table 3 shows regression analysis.

According to the threshold model's findings, economic growth increases renewable energy use by $1 \%$ in more democratic countries. However, economic growth delays renewable energy usage in countries without democracies. What this means is because democratic institutions have a major impact on developing country renewable energy deployment, a negative relationship between economic development and
Table 3 Regression analysis

\begin{tabular}{lll}
\hline Variable & Fixed effect & Random effect \\
\hline $\mathrm{EE}$ & $0.0341^{* * *}(0.000)$ & $0.0122^{* * *}(0.067)$ \\
$\mathrm{RE}$ & $-0.0444 * * *(-0.001)$ & $-0.0332 * * *(-0.011)$ \\
$\mathrm{GF}$ & $0.0871 * * *(0.000)$ & $0.00776^{* *}(0.000)$ \\
$\mathrm{NRE}$ & $0.885^{* * *}(0.6664)$ & $0.6725 * *(0.476)$ \\
$\mathrm{K}$ & $0.3101 * * *(-0.0018)$ & $0.4351 * * *(-0.0222)$ \\
$\mathrm{FDI}$ & $1.001 * * *(-0.0212)$ & $1.329 * * *(-0.0002)$ \\
GDP & $2.1972 * * *(-0.4112)$ & $2.1132 * * *(-0.4675)$ \\
Constant & $5.9841 * * *(-1.88)$ & $6.8889 * * *(-1.096)$ \\
$R^{2}$ & 0.783 & \\
Hausman test & 12.99 & \\
\hline
\end{tabular}

Table 4 Padroni co-integration analysis

\begin{tabular}{|c|c|c|c|c|}
\hline & Values & Sig & WS & Sig \\
\hline \multicolumn{5}{|c|}{$\mathrm{H}_{1:}$ common AR coefficients (within-dimension) } \\
\hline $\mathrm{v}$-stats of the panel & 0.266 & 0.002 & 0.122 & 0.000 \\
\hline Rho-stats of the panel & 0.177 & 0.003 & 0.319 & 0.001 \\
\hline pp-stats of the panel & 0.505 & 0.002 & 0.363 & 0.000 \\
\hline \multicolumn{5}{|c|}{$\mathrm{H}_{2:}$ common AR coefficients (between-dimension) } \\
\hline $\mathrm{v}$-stats of the group & 0.737 & 0.758 & 0.279 & 0.000 \\
\hline Rho-stats of the group & 0.778 & 0.984 & 0.932 & 0.000 \\
\hline pp-stats of the group & 0.589 & 0.812 & 0.346 & 0.000 \\
\hline
\end{tabular}

Table 5 Long-run elasticity of green bond financing with energy poverty index

\begin{tabular}{llllll}
\hline \multirow{2}{*}{ Study constructs } & FMOLS & & & DOLS \\
\cline { 2 - 3 } \cline { 5 - 6 } & Co-eff & $t$-value & & Co-eff & $t$-value \\
\hline RE & $0.3246^{*}$ & 18.78 & & $0.2589^{*}$ & $0.2711^{*}$ \\
NRE & $0.2923^{*}$ & 5.833 & & $0.1126^{*}$ & $0.1059^{*}$ \\
$\mathrm{~K}$ & $0.1378^{*}$ & 2.824 & & $0.2555^{*}$ & $0.2308^{*}$ \\
$\mathrm{~L}$ & $0.0778^{*}$ & 5.069 & & $0.3296^{*}$ & $0.3392^{*}$ \\
$R^{2}$ & 0.9938 & & & 0.9731 & \\
\hline
\end{tabular}

Note: $*=10 \%$ significant level

renewable energy growth in the linear model may be misleading. A possible explanation for this finding is that democratic countries dedicate a larger share of their resources to environmentally friendly manufacturing. Recent restrictions have been related to the minimal benefit of renewable energy use, and by 2019, about $34 \%$ of the population will be power users. Belgium is investigating renewable energy resources in various dams in order to improve the percentage of people who can easily use renewable energy in their daily lives. Table 4 shows Padroni co-integration analysis, and Table 5 shows long-run elasticity of green bond financing. 
To put it another way, during the early phases of evolutionary impact, economic growth imposed scale constraints on renewable energy development, which were enforced by Austrian and Greek authorities via financial development and green bond financing channels. Economic growth has begun to internalize the negative environmental externalities it has generated, and the method effect of economic development has gradually begun to internalize a rise in renewable energy usage. Table 6 shows panel data regression estimates.

This section of the study findings is consistent with what was found throughout this investigation. According to the study, there is a reversal point in the economic growthrenewable energy usage relationship.

\section{Sensitivity analysis}

When the composition effect and fossil fuel energy consumption (FE) are considered, economic growth seems to have a larger impact on renewable energy consumption than previously believed. This shift demonstrates how the composition effect's impact on environmental sustainability has changed over time as a function of the model's different model parameters. To attain cost efficiency at the expense of environmental quality, policymakers' desired economic growth pattern requires labor-intensive companies in the short run. Short-term policy myopia will come to an end, and economic growth patterns will require companies to be more capital-intensive, investing more in technological innovation. These OECD nations' usage of renewable energy is becoming increasingly attractive as a consequence of this long-term policy objective.
Table 7 Long-run elasticity through robustness analysis

\begin{tabular}{|c|c|c|c|c|c|}
\hline Countries & $\mathrm{Y}$ & $\mathrm{RE}$ & NRE & $\mathrm{K}$ & $\mathrm{L}$ \\
\hline Austria & 0.444 & 0.138 & 0.417 & 0.508 & 0.786 \\
\hline Belgium & 0.728 & 0.299 & 0.527 & 0.548 & 0.548 \\
\hline Czech Republic & 0.352 & 0.065 & 0.619 & 0.775 & 0.812 \\
\hline Denmark & 0.588 & 0.152 & 0.591 & 0.317 & 0.342 \\
\hline Estonia & 0.557 & 0.578 & 0.453 & 0.719 & 0.155 \\
\hline Finland & 0.747 & 0.084 & 0.934 & 0.246 & 0.376 \\
\hline France & 0.371 & 0.851 & 0.166 & 0.109 & 0.914 \\
\hline Germany & 0.815 & 0.326 & 0.966 & 0.404 & 0.779 \\
\hline Greece & 0.536 & 0.594 & 0.939 & 0.341 & 0.275 \\
\hline Hungary & 0.812 & 0.978 & 0.415 & 0.799 & 0.754 \\
\hline Iceland & 0.866 & 0.791 & 0.496 & 0.226 & 0.484 \\
\hline Ireland & 0.266 & 0.964 & 0.416 & 0.135 & 0.781 \\
\hline Italy & 0.865 & 0.226 & 0.858 & 0.573 & 0.519 \\
\hline Latvia & 0.157 & 0.091 & 0.119 & 0.249 & 0.322 \\
\hline Lithuania & 0.487 & 0.854 & 0.038 & 0.654 & 0.938 \\
\hline Luxembourg & 0.881 & 0.714 & 0.268 & 0.098 & 0.555 \\
\hline Netherlands & 0.299 & 0.473 & 0.237 & 0.727 & 0.808 \\
\hline Norway & 0.961 & 0.212 & 0.786 & 0.411 & 0.936 \\
\hline Poland & 0.619 & 0.132 & 0.981 & 0.365 & 0.097 \\
\hline Portugal & 0.126 & 0.072 & 0.932 & 0.161 & 0.803 \\
\hline Slovak Republic & 0.984 & 0.864 & 0.276 & 0.357 & 0.426 \\
\hline Slovenia & 0.466 & 0.663 & 0.855 & 0.124 & 0.375 \\
\hline Spain & 0.776 & 0.181 & 0.7445 & 0.695 & 0.799 \\
\hline Sweden & 0.296 & 0.515 & 0.113 & 0.502 & 0.241 \\
\hline Switzerland & 0.733 & 0.944 & 0.929 & 0.017 & 0.968 \\
\hline UK & 0.444 & 0.561 & 0.678 & 0.521 & 0.403 \\
\hline
\end{tabular}

Table 6 Panel data regression estimates

\begin{tabular}{|c|c|c|c|c|}
\hline \multirow{2}{*}{$\begin{array}{l}\text { Variable } \\
\text { EE }\end{array}$} & \multicolumn{2}{|l|}{ Green financing } & \multicolumn{2}{|l|}{ Renewable energy mix } \\
\hline & $-0.0451 * * *(0.0006)$ & & & $-0.0392 * * *(0.0001)$ \\
\hline RE & & $-0.0556 * * *(0.0003)$ & & \\
\hline GF & & & $-0.0459 * * *(0.0000)$ & \\
\hline NRE & & & & $-0.0573 * * *(0.0001)$ \\
\hline K & $-0.259 * * *(0.000)$ & $-0.044 * * *(0.0001)$ & $-0.112 * * *(0.0005)$ & $-0.0586^{* * *}(0.0007)$ \\
\hline FDI & $0.663(0.000)$ & $0.617 *(0.000)$ & $0.321(0.001)$ & $0.443 *(0.000)$ \\
\hline GDP & $0.567 * * *(0.001)$ & $0.544 * * *(0.005)$ & $0.411 * * *(0.002)$ & $0.3590 * * *(0.001)$ \\
\hline \multicolumn{5}{|l|}{$\mathrm{EE}$} \\
\hline $\mathrm{RE}$ & $3.0111 * * *(0.000)$ & $2.001 * * *(0.000)$ & $2.0149 * * *(0.000)$ & $2.0359 * * *(0.000)$ \\
\hline Constant & $1.569(0.000)$ & $1.585 * * *(0.000)$ & $1.325 * * *(0.000)$ & $1.1313 * * *(0.000)$ \\
\hline AR (1) test & $-2.0478[0.031]$ & $-2.0667[0.037]$ & $-2.011[0.024]$ & $-2.390[0.011]$ \\
\hline AR (2) test & -1.1554 [0.159] & $-1.3361[0.171]$ & $-1.1331[0.124]$ & $-1.2212[0.111]$ \\
\hline Sargan test & $21.0032[0.074]$ & $19.4914[0.066]$ & $22.0001[0.21]$ & $19.2516[0.29]$ \\
\hline Wald test & $131,191[0]$ & $261,783[0]$ & $203,580[0]$ & $49,510[0]$ \\
\hline
\end{tabular}

Note: Standard errors are in parentheses (). $* * *=1 \%$ significant level, $* *=5 \%$ significant level, and $*=10 \%$ significant level 
Table 7 shows sensitivity analysis. The empirical findings of this research and those of Li et al. ( 2021a, b, c) are comparable. The growth trend of renewable energy development may be damaged if we switch to renewable energy solutions suddenly. Due to the negative environmental impact of fossil fuel use, it will continue to predominate in nations like these, and the increasing demand for renewable energy sources will be a consequence of the increased environmental externality. The long- and short-term impacts of fossil fuel energy consumption on renewable energy consumption indicate that sustained use of fossil fuel energy will result in increasing usage of renewable energy. Additionally, for the development and implementation of renewable energy solutions, institutional quality must be enhanced. These findings are confirmed by examining the effect of intelligence on all three models. Additionally, it shows the critical role of organizations in promoting the usage of renewable energy.

\section{Discussion}

There are a few alternative sources of financing for real estate developers owing to the region's undeveloped stock and bond markets (Fig. 1). As a general rule, government bonds account for much over $40 \%$ of the country's GDP (ADB 2015). Singapore, Malaysia, and Thailand were the only three nations with stock markets whose market capitalization surpassed GDP. Real estate developers must go to the government for funding since private investment channels are restricted. The World Bank and the Asian Development Bank have provided financial and technical assistance to Asian regional economic cooperation (RE) projects. These organizations are encouraging renewable energy investment throughout Asia using concessional financing made accessible to low-income countries. With a variety of financing instruments, the Asian Development Bank (ADB) is encouraging the growth of renewable energy in the region. The Clean Energy Financing Partnership (CEFP) was established in 2007 with the goal of providing financial resources for sustainable energy projects. The Asian Development Bank (ADB) invested $\$ 5$ trillion in Asia's renewable energy industry by 2009, according to the organization (ADB 2014). Private sector investment in renewable energy projects may benefit from multilateral bank support, according to Spratt and Griffith-Jones (2013). In Indonesia's North Sumatra area, for instance, the 320 MW Sarulla Geothermal Power Development Project is an excellent illustration of CTF, and CEFPF contributed $\$ 350$ million of ADB's normal capital resources as financial support to the Clean Technology Fund (CTF). Using private finance, it was able to secure a $\$ 1.17$ billion credit package from six commercial banks. Despite their ability to leverage the private sector, these public sector financing channels are often seen as unsustainable investments due to their small fund sizes and slow turnover rates.

Apart from enacting legislation to promote the use of renewable energy (RE), the government provides direct financial support for RE projects in the region. Other ways the public sector helps are via direct stock infusions and loan guarantees. Many Asian developing countries have an investment deficit, and it is unlikely that this financing source will be sufficient to fill it. According to Gujba et al. (2012), international government and donor financing is increasingly important for renewable energy lending in Asia. Asian institutional investors are expected to play an

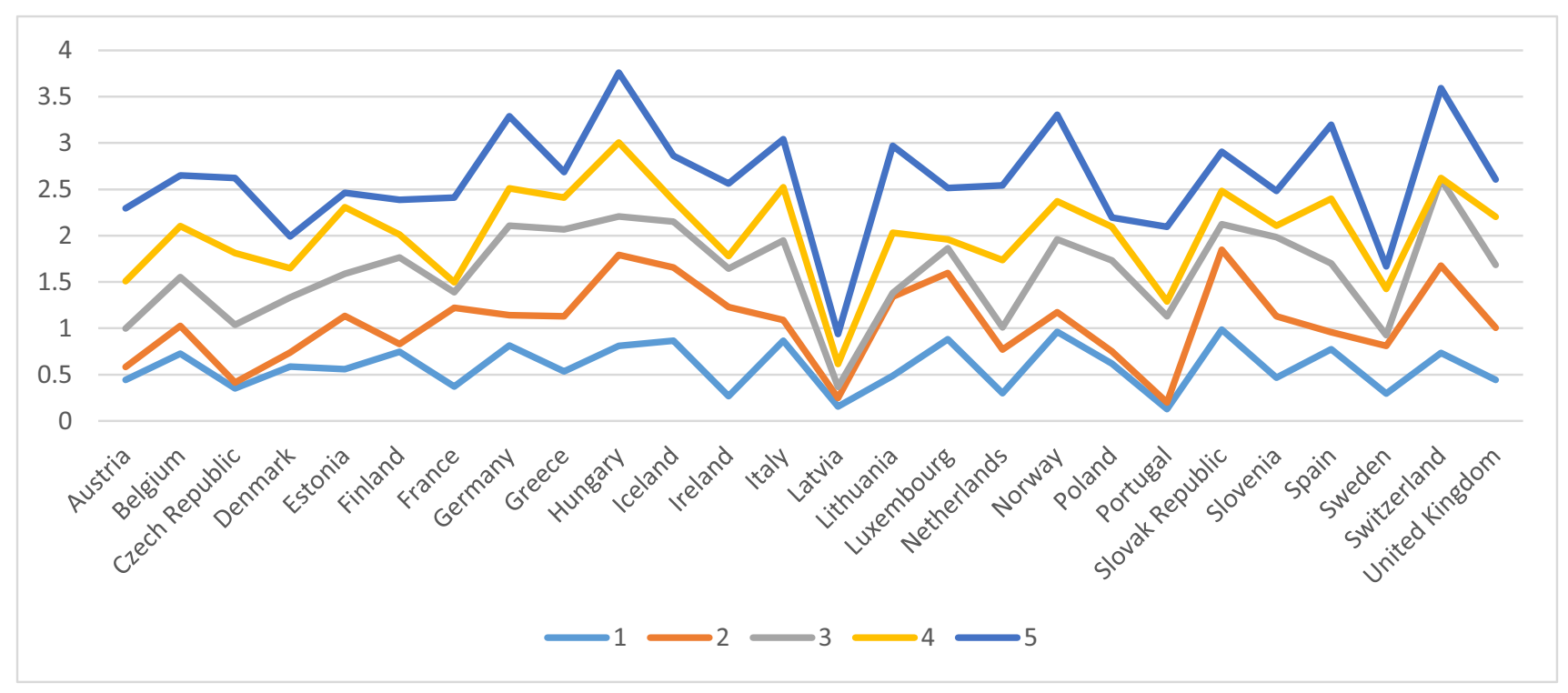

Fig. 1 Movement of study indicator over the period of sample 
important role in the private sector in financing renewable energy due to the large pool of investable capital and rapidly increasing assets under management (PwC 2020).

The inefficiencies of the financial markets, which prefer traditional energies to renewable energy projects, and the lack of financial diversity and growth in the region are due to the lack of finance in Asia. The absence of a wide range of financial instruments in Asia will likely limit the amount of RE financing accessible. Western nations do not face the same investment limitations as those in Asia when it comes to renewable energy. As previously stated, according to the SE4ALL research, Europe is sufficiently funding the real estate sector (SE4ALL, 2015). Even if laws were put in place to promote investment in renewable energy, the same could be said for Asian nations. Different RE-supporting policies have been adopted by policymakers in Asia, including as Feed-in Tariffs (FiT). Real estate markets in Europe and Asia are different because of the present financial environment for real estate. Green bonds, yield cos, and other alternative securities are being utilized successfully in the European markets because they are innovative. However, in Asia, most RE projects are funded via the efforts of banks or government agencies. The financing gap in Asia is mostly due to a lack of varied financial instruments that may be utilized to link projects with the appropriate investors based on their individual risk and return philosophies.

Volatility has increased, and as a consequence, systemic risks have been created. In the end, this would exacerbate the problem of discouraging active participation in the financial market by the domestic private sector and restrict the development of the financial sector. A tiny market will be created if such is the case. Because of the heightened financial risks associated with a homogenous financial system, international financial intermediaries abstain from engaging in this initiative. Growing Asian financial markets will remain small and underdeveloped unless they attract foreign investment and the resulting increased sophistication. Having a single, uniform financial structure may lead to a cascade of self-feeding reactions that limit market growth while also increasing financing gaps for renewable energy (RE). As bond instruments for renewable energy projects are created, this may assist to increase the amount of institutional money available for these projects while also helping to improve the current financial system. It also helps improve financial intermediation services over time as financial systems evolve.

\section{Conclusion and policy implications}

Considering the issue of energy poverty in modern times, an advanced understanding is provided by this research on the subject matter about how energy poverty financing through green bond financing is somewhat evitable. The study especially contributed theoretically, empirically, and policy-wise by dealing with novel, energy-economic, energy-financing, and time-bound problems of energy poverty through multidimensional index. For this purpose, recent unlocked the association between energy poverty financing and green bond financing and presented the policy measures based on the study period. Conclusively, the study presented an optimal design for energy poverty financing schemes suggesting a way forwards for key stakeholders on access to energy and energy poverty mitigation. Green bonds are the biggest driver supporting the energy sector, but realistically it could be drastic to rely on this single source for energy poverty mitigation, all the time. However, it is high time to come up with alternative ways for energy poverty mitigation. On this, study suggests the following policy implication.

Using the capital market to finance renewable energy projects may help to increase market transparency and reduce information asymmetry in the sector. LCY Corporate Bonds, Project Bonds, and Green Currency Bonds are three types of bonds that can be used for renewable energy loans in the region and will be discussed in the next section. LCY Corporate Bonds are bonds issued by renewable energy companies in local currency. Corporate bonds are called recourse financing since they are usually backed by the issuing company's financial sheet. Fixed income instruments known as "project bonds," on the other hand, refer to investments that are fully or partially secured by their underlying projects or assets. Holders of bonds do not have access to the company's balance sheet in case of failure; thus, this kind of financing is referred to as "nonrecourse." As asset-backed securities, project bonds may be issued at the beginning of the project lifetime or throughout the operating period (ABS). Green bonds are a new kind of bond that promotes environmental responsibility. Environmentally friendly bonds may be issued as company bonds, project bonds, or asset-backed securities. Financing institutions that want to expand lending to renewable energy sectors may now raise money publicly by issuing a financial bond, giving them more choices in the financial world.

Due to the rapid expansion of the LCY bond market in the region, most renewable energy project developers have chosen to issue bonds in their local currency. The key benefit of LCY corporate bonds is that they can be used to reinvest local and regional funds. Asia as a whole remains a capital surplus region, with most countries experiencing current account surpluses. The savings rate in the region is very high, which indicates that the region has sufficient capital. The current trend is that large amounts of local funds are used with low yields for low-risk offshore investments, as evidenced by the expansion of foreign exchange reserves in the region. Therefore, the government must divert capital flows to new local investment projects. New national and 
regional institutional investors can be attracted to renewable energy bond products that offer stable, low risk returns on investment instruments, return capital to the region and increase the loan pool for investment projects.

Trina Solar Limited in China is an example of a recent issue of RE bonds. One of the world's leading manufacturers of solar power products including solar modules is Trina Solar Limited. In 2014, the company issued US $\$ 115$ million in 3.5\% convertible senior notes. In June 2014, Trina Solar completed a private placement with institutional investors for an issue of US\$ 140 million. For RE corporate bonds, demand from investors was favorable, which was reflected in an October bond oversubscription that allowed borrowing to rise from $\$ 100$ million to $\$ 150$ million.

It becomes clear that green bonds, in which the issuer pledges to exclusively using bond proceeds for environmentally friendly goods, may be a useful source of funding for RE. One of the most distinguishing features is that investors are promoted as eco-friendly when purchasing a green bond, and the profits of such sales go only to environmentally friendly initiatives. This differs from traditional bonds in that the bondholder has no influence in how the bond's profits are spent.

Author contribution Conceptualization and methodology, $\mathrm{Na} \mathrm{Li}$; literature review and visualization, Xudong Pei; editing (writing of draft), Yuzhou Huang; software and editing, data curation, and supervision, Jianqi Qiao; conclusion and policy implications, Yujie Zhang; and reviewing, editing, and literature, Riaz Hussain Jamali.

Data availability The data that support the findings of this study are openly available on request.

\section{Declarations}

Ethical approval and consent to participate We declare that we have no human participants, human data, or human issues.

Consent for publication We do not have any individual person's data in any form.

Competing interests The authors declare no competing interests.

\section{References}

Ahmad M, Iş1k C, Jabeen G, Ali T, Ozturk I, \& Atchike DW (2021) Heterogeneous links among urban concentration, non-renewable energy use intensity, economic development, and environmental emissions across regional development levels. Sci Total Environ $765: 144527$

Alemzero DA, Iqbal N, Iqbal S, Mohsin M, Chukwuma NJ, Shah BA (2021) Assessing the perceived impact of exploration and production of hydrocarbons on households' perspective of environmental regulation in Ghana. Environ Sci Pollut Res 28(5):5359-5371

Alkathery MA, \& Chaudhuri K (2021) Co-movement between oil price, $\mathrm{CO} 2$ emission, renewable energy and energy equities: evidence from GCC countries. J Environ Manag 297:113350

Alola AA, Uzuner G (2021) Testing the asymmetric causal nexus of housing-oil prices and pandemic uncertainty in four major economies. Environ Sci Pollut Res. https://doi.org/10.1007/ s11356-021-14992-2

Alvarado R, Deng Q, Tillaguango B, Méndez P, Bravo D, Chamba J, ... \& Ahmad M (2021) Do economic development and human capital decrease non-renewable energy consumption? Evidence for OECD countries. Energy, 215:119147

Anh Tu C, Chien F, Hussein MA, Ramli MM Y, Psi MM MSS, Iqbal S, \& Bilal AR (2021) Estimating role of Green Financing on Energy Security, Economic and Environmental Integration of BRI member countries. The Singapore Economic Review.

Bloomberg NEF (2020) New Energy Outlook 2020

Caglar AE (2020) The importance of renewable energy consumption and FDI inflows in reducing environmental degradation: bootstrap ARDL bound test in selected 9 countries. J Clean Prod 264:121663

Chu S, \& Majumdar A (2012) Opportunities and challenges for a sustainable energy future. nature, 488(7411), 294-303.

Dawar I, Dutta A, Bouri E, Saeed T (2021) Crude oil prices and clean energy stock indices: lagged and asymmetric effects with quantile regression. Renewable Energy 163:288-299

Demirtas O (2013) Evaluating the best renewable energy technology for sustainable energy planning. Int J Energy Econ Policy 3:23

Goldemberg J (2007) Ethanol for a sustainable energy future. science, 315(5813), 808-810.

Hanif W, Hernandez JA, Mensi W, Kang SH, Uddin GS, \& Yoon SM (2021) Nonlinear dependence and connectedness between clean/renewable energy sector equity and European emission allowance prices. Energy Economics, 101, 105409.

Hussain A, Arif SM, Aslam M (2017) Emerging renewable and sustainable energy technologies: state of the art. Renew Sustain Energy Rev 71:12-28

Iqbal S, Bilal AR, Nurunnabi M, Iqbal W, Alfakhri Y, Iqbal N (2021) It is time to control the worst: testing COVID-19 outbreak, energy consumption and CO 2 emission. Environ Sci Pollut Res 28(15):19008-19020

Jacobson MZ, Delucchi MA (2009) A path to sustainable energy by 2030. Sci Am 301(5):58-65

Jha SK, Puppala H (2017) Prospects of renewable energy sources in India: prioritization of alternative sources in terms of Energy Index. Energy 127:116-127

Kothari R, Tyagi VV, Pathak A (2010) Waste-to-energy: a way from renewable energy sources to sustainable development. Renew Sustain Energy Rev 14(9):3164-3170

Kumar S, Kaur T, Upadhyay S, Sharma V, \& Vatsal D (2020) Optimal sizing of stand alone hybrid renewable energy system with load shifting. Energy Sources, Part A: Recovery, Utilization, and Environmental Effects, 1-20.

Li HS, Geng YC, Shinwarai R, Yangjie W, \& Rjoub H (2021a) Does renewable energy electricity and economic complexity index help to achieve carbon neutrality target of top exporting countries?. Journal of Environmental Management, 299, 113386.

Li W, Chien F, Hsu CC, Zhang Y, Nawaz MA, Iqbal S, \& Mohsin M (2021b) Nexus between energy poverty and energy efficiency: estimating the long-run dynamics. Resources Policy, 72, 102063.

Li W, Chien F, Ngo QT, Nguyen TD, Iqbal S, \& Bilal AR (2021c) Vertical financial disparity, energy prices and emission reduction: empirical insights from Pakistan. J Environ Manag 294:112946. 
Liao SC, Chang SC, Cheng TC (2021) Managing the volatility risk of renewable energy: index insurance for offshore wind farms in Taiwan. Sustainability 13(16):8985

Liu T, Hamori S (2020) Spillovers to renewable energy stocks in the US and Europe: are they different? Energies 13(12):3162

Naber R, Raven R, Kouw M, Dassen T (2017) Scaling up sustainable energy innovations. Energy Policy 110:342-354

Nasr AK, Kashan MK, Maleki A, Jafari N, Hashemi H (2020) Assessment of barriers to renewable energy development using stakeholders approach. Entrep Sustain Issues 7(3):2526

Price waterhouse Coopers (2020) Asset Management 2020 A Brave New World

Qin L, Hou Y, Miao X, Zhang X, Rahim S, \& Kirikkaleli D (2021) Revisiting financial development and renewable energy electricity role in attaining China's carbon neutrality target. J Environ Manag 297:113335

Ram Ola S, Saraswat A, Goyal SK, Sharma V, Khan B, Mahela OP, ... Siano P (2020) Alienation coefficient and wigner distribution function based protection scheme for hybrid power system network with renewable energy penetration. Energies 13(5):1120

Roselli C, Diglio G, Sasso M, Tariello F (2019) A novel energy index to assess the impact of a solar PV-based ground source heat pump on the power grid. Renewable Energy 143:488-500

Shafie SM, Mahlia TMI, Masjuki HH, Andriyana A (2011) Current energy usage and sustainable energy in Malaysia: a review. Renew Sustain Energy Rev 15(9):4370-4377

Shahbaz M, Raghutla C, Chittedi KR, Jiao Z, \& Vo XV (2020) The effect of renewable energy consumption on economic growth: evidence from the renewable energy country attractive index. Energy 207:118162.

Song Y, Ji Q, Du YJ, \& Geng JB (2019) The dynamic dependence of fossil energy, investor sentiment and renewable energy stock markets. Energy Econ 84:104564
Tester JW, Drake EM, Driscoll MJ, Golay MW, \& Peters WA (2012) Sustainable energy: choosing among options. MIT press

United Nations Environment Programme (UNEP) (2007) Guidebook to Financing CDM Projects

Wang B, Wang Q, Wei YM, Li ZP (2018a) Role of renewable energy in China's energy security and climate change mitigation: an index decomposition analysis. Renew Sustain Energy Rev 90:187-194

Wang Z, Zhang B, Wang B (2018b) Renewable energy consumption, economic growth and human development index in Pakistan: evidence form simultaneous equation model. J Clean Prod 184:1081-1090

Yogee GS, Mahela OP, Kansal KD, Khan B, Mahla R, Haes Alhelou H, Siano P (2020) An algorithm for recognition of fault conditions in the utility grid with renewable energy penetration. Energies 13(9):2383

Yuksel I, Kaygusuz K (2011) Renewable energy sources for clean and sustainable energy policies in Turkey. Renew Sustain Energy Rev 15(8):4132-4144

Zakari A, Adedoyin FF, Bekun FV (2021) The effect of energy consumption on the environment in the OECD countries: economic policy uncertainty perspectives. Environ Sci Pollut Res 28:5229552305. https://doi.org/10.1007/s11356-021-14463-8

Publisher's Note Springer Nature remains neutral with regard to jurisdictional claims in published maps and institutional affiliations. 